\title{
Pessary treatment for pelvic organ prolapse and health-related quality of life: a review
}

\author{
Babet H. C. Lamers • Bart M. W. Broekman • \\ Alfredo L. Milani
}

Received: 9 October 2010 / Accepted: 24 February 2011 /Published online: 7 April 2011

(C) The Author(s) 2011. This article is published with open access at Springerlink.com

\begin{abstract}
Pessaries have been used to treat women with pelvic organ prolapse (POP) since the beginning of recorded history. This review aims to assess the effect of pessary treatment on the disease-specific, health-related quality of life in women with pelvic organ prolapse. After a Medline search using the Mesh term 'pessary' and critical appraisal, 41 articles were selected and used in this review. Pessaries are widely used to treat pelvic organ prolapse. It is minimally invasive and appears to be safe. Although there is evidence that the use of pessaries in the treatment of pelvic organ prolapse is effective in alleviating symptoms and that patient satisfaction is high, the follow-up in many published papers is short, and the use of validated urogynaecological questionnaires is limited. Comparison with surgical treatment of pelvic organ prolapse is rare and not assessed in a randomised controlled trial.
\end{abstract}

Keywords Pelvic organ prolapse · Pessaries · Pessary . Quality of life · Surgery $\cdot$ Urogenital

\footnotetext{
B. H. C. Lamers $(\bowtie)$

Department of Obstetrics and Gynecology,

Erasmus Medical centre,

s-Gravendijkwal 230,

3015 CE Rotterdam, The Netherlands

e-mail: B.Lamers@erasmusmc.nl

B. M. W. Broekman

Department of Obstetrics and Gynecology,

Sint Fransciscus Gasthuis,

Rotterdam, The Netherlands

\section{A. L. Milani}

Department of Obstetrics and Gynecology,

Reinier de Graaf Group,

Delft, The Netherlands
}

\section{Introduction}

Pessaries have been used to treat women with pelvic organ prolapse since the beginning of recorded history. Hippocrates described reduction of vaginal prolapse by placing a halved pomegranate soaked in wine into the vagina (Fig. 1) [1].

A variety of devices has been described over time [2]. Nowadays, most pessaries are made of silicone and are ring type pessaries with or without central support, Gellhorn pessaries and donut pessaries (Fig. 2) [3]. Pessaries are used in daily practice by more than $86 \%$ of gynaecologists and $98 \%$ of urogynaecologists $[4,5]$. The ring with central support and the Gellhorn pessary are most frequently used and appear equally effective in relieving symptoms of genital prolapse and voiding dysfunction [6].

It is not clear which patients particularly benefit most from pessary treatment, what the side effects are and whether the therapeutic effect is high enough to condone possible side effects. Most important is whether pessary treatment reduces urogenital bother symptoms and which impact it has on health-related quality of life [7]. In the end, it is not the doctor's but the patient's opinion about the treatment that is most important. Health-related quality of life is one of the patient outcome measures (POM) and is measured and quantified in domain scores of validated urogynaecological questionnaires. The use of these validated questionnaires to assess health-related quality of life in surgery of pelvic organ prolapse (POP) is well established. Although pessary treatment is widely used for the treatment of pelvic organ prolapse as well, a (systematic) review on the quality of life following pessary treatment has not yet been published.

This review aims to assess the effects of pessary treatment on disease-specific health-related quality of life in women with POP. 


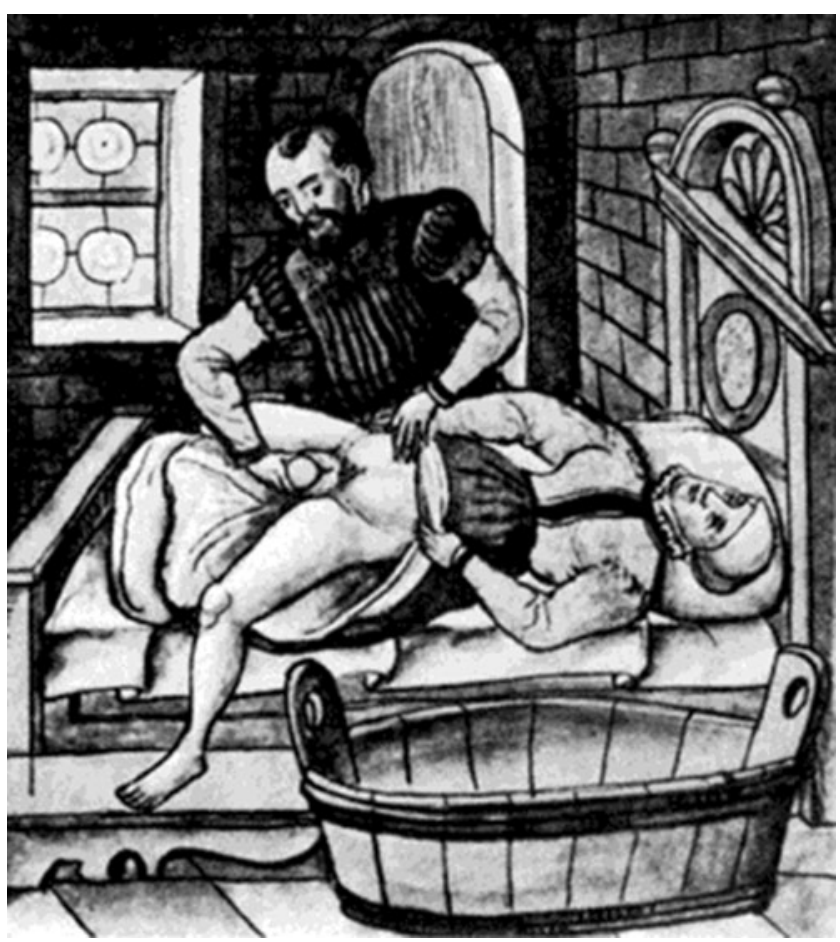

Fig. 1 Reduction of vaginal prolapse by placing a halved pomegranate soaked in wine into the vagina described by Hippocrates

\section{Search strategy and selection criteria}

We searched Medline (1966 to December 2010) using the Mesh term 'pessary' and limits 'female' AND 'human'. This resulted in 726 articles. An additional search on Embase using the term 'pessary' and limits 'human' resulted in 633 articles. After screening of both title and abstract, we were left with 159 articles related to pelvic organ prolapse and pessary. This review focused solely on pessary treatment in pelvic organ prolapse. Therefore, articles regarding pessary treatment in urinary incontinence or other conditions were excluded. Guidelines on how to fit a pessary, case reports describing rare complications without any literature review and experts' letters were excluded. From the remaining 41 articles which were considered useful, 13 articles were a review [2, 5, 8-18], and 28 articles were original research articles [3, 4, 6, 7, 19-43]. Only 10 articles [6, 19-21, 25, 27, 32, 34, 35, 41] met the exact criteria of the reviewers' aim to assess the health-related quality of life in women with pelvic organ prolapse. Although the other articles did not meet these prespecified criteria, they were considered useful in additional analyses, such as for example which women are most suitable for pessary treatment, successful fitting, dropout rates and management of pessary treatment. Table 1 shows a description of papers included in this review. This review was originally set up as a systematic review. After reviewing the articles, there was inconsistency in definitions such as successful fitting and dropout rates, sample sizes, and follow-up periods, and there was shortage of studies that met the exact criteria. Therefore, the goal of a systematic review could unfortunately not be achieved, but the available (or lack of) research articles did, to our opinion, justify the present review.

\section{Patient suitability}

Which patients are considered suitable for pessary treatment remains unclear from the literature. Patients themselves may have preconceived ideas, and both beliefs and attitudes regarding the aetiology and success of pessary treatment may influence their choice of treatment [3, 22, 31, 33].

Some factors contributing to patient's choices appear to be independently associated with treatment choices of patients in a fairly predictable way. The probability of choosing pessary treatment over surgery increases as patients' age rises and respectively decreases as stage of POP increases [31]. Women who already have undergone prior POP surgery are more eager to choose POP surgery again [31]. Women preferring surgery to pessary treatment for POP reported more bothersome symptoms related to POP and felt more affected by POP in their general well-being [33]. Furthermore, the majority of patients who were sexually active tended to prefer surgery above conservative treatment [33].

\section{Failure of fitting and continuation of pessary use}

Most papers reported that there are certain groups of patients that drop out. There are patients who initially do

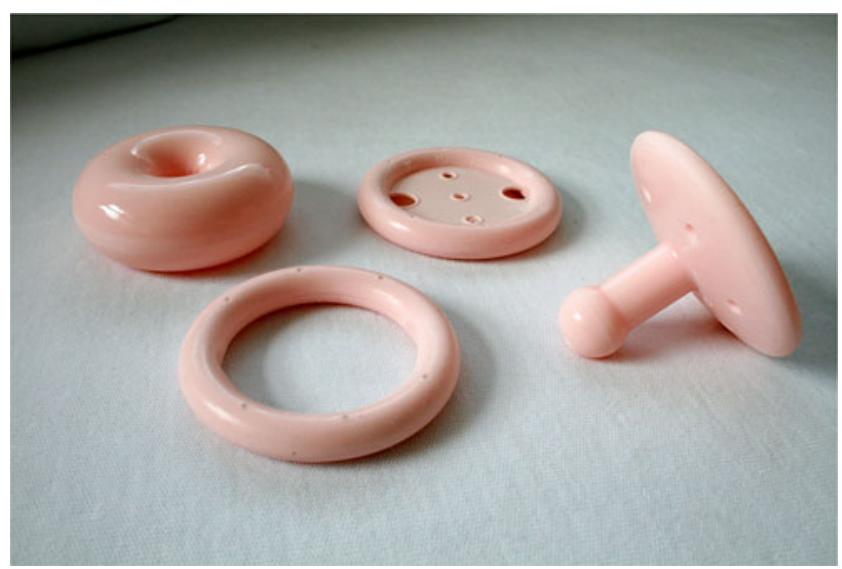

Fig. 2 Pessary most prescribed. Donut, Gellhorn, ring with and without support (Milex Products, Inc.) 
Table 1 Description of papers used in the review

\begin{tabular}{lll}
\hline Description of research & Number of articles, $n=41$ & References \\
\hline Quality of life changes in pessary use in pelvic organ prolapse & 10 & {$[4,6,19-21,25,27,32,34,35]$} \\
Successful fitting pessary and dropout rates in pelvic organ prolapse & 20 & {$[6,19-25,27,28,30,32,34,35,37,39-43]$} \\
Continuation rate long-term pessary use & 3 & {$[23,27,43]$} \\
Patients suitability & 6 & {$[3,14,20,22,31,33]$} \\
Anatomical changes after pessary use & 3 & {$[29,32,38]$} \\
Complication and discomfort & 6 & {$[1,9,18,23,27,43]$} \\
Management of pessary treatment & 11 & {$[1,3,5,10,14-18,21,30]$} \\
Research design & & {$[2,5,8-18]$} \\
Review & 13 & {$[3,20,22,23,28,30,37,39,42,43]$} \\
Retrospective study & 10 & {$[7,19,21,24-27,29,33-36,41]$} \\
Prospective study & 13 & {$[4,6,40]$} \\
Randomised and quasi-randomised trials & 3 & {$[31]$} \\
Cross-sectional & 1 & {$[32]$} \\
Observational cohort & 1 & {$[38]$} \\
Case report & 1 &
\end{tabular}

not comfortably retain a pessary (mostly at their first visit). There is an additional group of patients who abandon pessary treatment after some weeks because of discomfort or repeated expulsions [30]. There is no agreement in the literature on what is considered successful pessary fitting. Some authors considered fitting successful if a pessary was perceived comfortable by a patient when retained during Valsalva and voiding, at the initial patient visit, while others considered fitting successful if a patient continued to use the pessary until the following doctor's appointment [40]. Therefore, the rate of unsuccessful fitting and dropout ranges widely. Table 2 offers an overview of successful fitting and dropout rates of studies included in this review. In this review, we considered fitting to be successful if a patient comfortably retained a pessary at their first visit. A patient was considered to drop out if they abandoned pessary use at the following doctors' appointment.

Most studies reported successful fitting rates to be over $85 \%$. Risk factors that are reported to be responsible for unsuccessful pessary fitting are short vaginal length, a large genital hiatus, prior history of hysterectomy and prior surgical repairs of POP [37, 39].

The compartment and stage of POP have not been reported to have any influence on successful pessary fitting and should therefore not be a factor of patient selection for pessary treatment [39]. Continuation rates on the short-term range from $50 \%$ to $80 \%$ after 3 or 4 months. After 1 year of use, the continuation rates remain unchanged: $50-80 \%$. Only two studies reported long-term continuation of pessary use over more than 1 year. One study reported a continued pessary use in $48 \%$ of patients for an average duration of 5.4 years [23]. A more recent study on the long term reported a $14 \%$ continued pessary use with a mean duration of 7 years [43].

An independent factor associated with the continued use of a pessary is age above 65 years. Sexually active women were more likely to continue wearing a pessary for a longer period of time $[22,26,28]$.

\section{Improvement in POP-related bother and health-related quality of life}

POP causes symptoms that have impact on patients' daily activities and quality of life. Women with POP seem to have a negative body image compared to women without POP [44]. Women who seek medical advice perceive these symptoms bothersome enough to opt for treatment and strive to improve their perceived quality of life [44].

We found only few articles in which validated urogynaecological questionnaires were used to asses treatment effects on health-related quality of life $[6,19,21,27,32$, $34,35,41]$. Two articles did not use validated questionnaires but measured improvement of POP symptoms and satisfaction in pessary users with questionnaires that 
Table 2 Successful fitting and dropout rates

\begin{tabular}{|c|c|c|c|c|c|}
\hline $\begin{array}{l}\text { Author publication year } \\
\text { [reference] }\end{array}$ & Number & Study design & $\begin{array}{l}\text { Initially successful } \\
\text { fitting, } n(\%)^{\mathrm{a}}\end{array}$ & $\begin{array}{l}\text { Dropout at follow-up, } \\
n(\%)^{\mathrm{b}}\end{array}$ & $\begin{array}{l}\text { Follow-up } \\
\text { in months }\end{array}$ \\
\hline Clemons 2004 [24] & 100 & Prospective & $94(94)$ & $21(22)$ & 0.5 \\
\hline Brincat 2004 [22] & 136 & Retrospective & Unknown & $54(40)$ & 4 \\
\hline Clemons 2004 [26] & 59 & Prospective & Unknown & $16(27)$ & 12 \\
\hline Mutone 2004 [39] & 407 & Retrospective & $288(71)$ & $120(42)$ & 0.75 \\
\hline Powers 2004 [42] & 32 & Retrospective & Unknown & $20(63)$ & Unknown \\
\hline Broens-Oostveen 2004 [23] & 192 & Retrospective & Unknown & $107(52)$ & 64 \\
\hline Bai 2005 [20] & 104 & Retrospective & Unknown & $20(19)$ & Unknown \\
\hline Hanson 2005 [30] & 1,216 & Retrospective & $1,043(86)$ & $299(29)$ & 3 \\
\hline Fernando 2006 [27] & 203 & Prospective & $203(100)$ & $106(52)$ & 4 \\
\hline Barber 2006 [21] & 42 & Prospective cross-over & $42(100)$ & $0(0)$ & 3 \\
\hline Maito 2006 [37] & 120 & Retrospective & $103(86)$ & $11(11)$ & 6 \\
\hline Cundiff 2007 [6] & 134 & Randomised cross-over & $123(92)$ & $49(40)$ & 3 \\
\hline Komesu 2007 [34] & 64 & Prospective cohort study & Unknown & $28(44)$ & 12 \\
\hline Jones 2008 [32] & 90 & Prospective cohort study & Unknown & $48(53)$ & 3 \\
\hline Nager 2009 [40] & 255 & Randomised controlled trial & $235(92)$ & No follow-up & No follow-up \\
\hline Kuhn 2009 [35] & 73 & Prospective cohort study & Unknown & $40(55)$ & 3 \\
\hline Sarma 2009 [43] & 273 & Retrospective & $167(61)$ & $144(86)$ & 84 \\
\hline Friedman 2010 [28] & 150 & Retrospective & Unknown & $35(23)$ & 12 \\
\hline Patel 2010 [41] & 75 & Prospective cohort study & $70(93)$ & $21(30)$ & 3 \\
\hline Abdool 2010 [19] & 359 & Prospective & $359(100)$ & $116(32)$ & 12 \\
\hline
\end{tabular}

${ }^{a}$ Initially fitting

${ }^{\mathrm{b}}$ Dropout at follow-up

were not validated $[20,25]$. Other questionnaires that were used were the Female Sexual Function Index Questionnaire (FSFI), the Pelvic Floor Distress Inventory (PFDI), the Pelvic Floor Impact Questionnaire (PFIQ), the Body Image Scale, the Sheffield Pelvic Organ Prolapse Symptom Questionnaire and the King's Health Questionnaire. The PFDI and PFIQ have been validated for use in women with POP [41]. The body image scale evaluates a woman's self-perception of her physical appearance, attractiveness, and satisfaction with her body. This questionnaire has been used in research on women with cancer and was considered valid and reliable for that group of patients, but is not yet validated for use in women with POP [45]. The FSFI is a validated questionnaire that refers to the domains of desire, arousal, lubrication, orgasm and satisfaction in sexual functioning [46]. The Sheffield prolapse questionnaire relates to the severity of POP specific symptoms, while the King's Health Questionnaire evaluates domains of health-related quality of life [35]. The results of 10 available studies are shown in Table 3. Consistent in most papers is the improvement gained in both bulge and irritative bladder symptoms following pessary treatment. Two studies reported de novo stress urinary incontinence [25, 35]. Women who were sexually active and wore a pessary reported a significant increase in both frequency and satisfaction of sexual activity $[19,27]$. There were significant improvements in desire, lubrification and sexual satisfaction after treatment of POP with a pessary [35]. These findings may have resulted of improvements in general well-being which may have altered patients' self-esteem. These data are suggestive that a vaginal pessary does not negatively interfere with sexual activity and may even improve sexual functioning as a whole.

Patients' satisfaction rates with medium-term pessary use are high (70-92\%) [20, 25]. Pessary treatment for 3 months not only reduced POP-related bother symptoms but also caused improvement in quality of life and women's perception of their body image [41].

A recently published study compared the effectiveness of pessaries with surgery in women with symptomatic POP [19]. The authors reported similar improvements in urinary, bowel, sexual function and quality of life parameters in both treatment arms. That suggests that pessary treatment in POP might be as effective as surgery in improving health-related quality of life. 


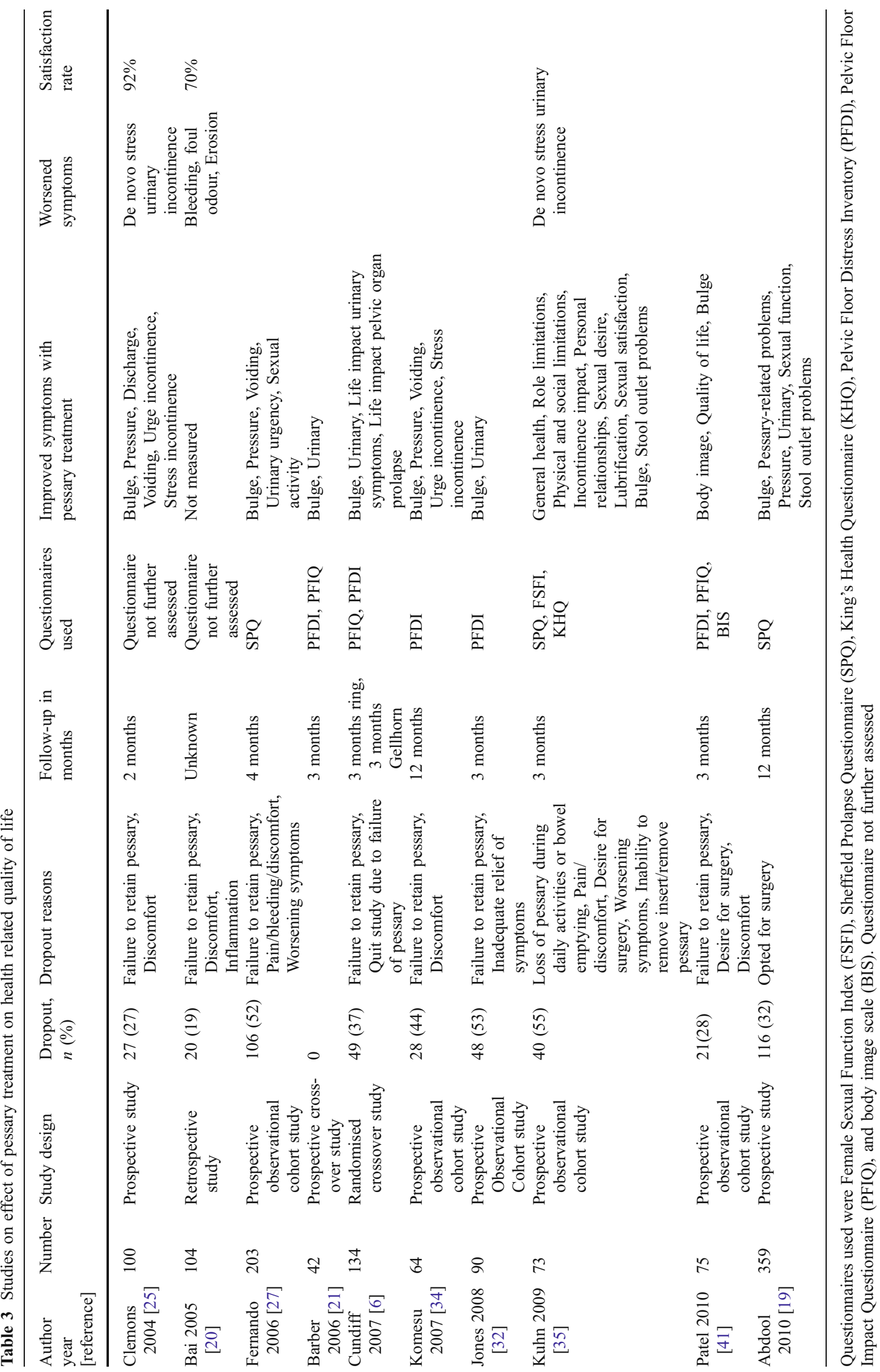




\section{Improvement in POP-Q measurement}

There may be a decrease in the size of the genital hiatus with continued pessary use. This decrease is detected even after 2 weeks of continuous pessary wearing [32]. There may also be an improvement in POP stage after 1 year of pessary treatment [29]. Such improvements may have been due to a transient effect of pessary use [29, 38]. Limitations of these papers are the small sample sizes. Whether this reduction in POP stage sustains at the long term and whether it is clinically relevant need further research.

\section{Management and follow-up}

Evidence is lacking on the type of pessary that is chosen, or who should be responsible for cleaning and changing pessaries and how often this should be performed [14, 30]. Ideally, the physician can teach a patient how to remove and replace the pessary herself. This increases patients' autonomy, allowing her to use it and clean it when needed [5, 18]. In such a setting, follow-up could be on an annual basis [18]. Patients who are not willing or able to manage pessary care themselves require more frequent doctors (or nurse practitioner) visits. There is a lack of evidence on whether a pessary should be used in combination with hormone replacement therapy or pelvic floor exercises [3]. If HRT is prescribed, local HRT seems to be more beneficial in reducing side effects than systemic HRT or a combination of both [30]. HRT is particularly used to prevent vaginal irritation and ulceration due to pressure of the pessary in an older and atrophic vagina [17]. There is some evidence that local HRT plays a significant role in the initial success of fitting [30].

\section{Complications and discomfort}

The most common side effects of pessary use are a foul smell, vaginal discharge, bleeding, pain and constipation [43]. A recent study reported that $56 \%$ of women wearing a pessary reported one of these side effects [43]. Changing a pessary at frequent intervals could prevent this vaginal irritation. Therefore, it is helpful if the patient is willing and able to remove, clean and replace the pessary herself [18].

Rarely, pessaries cause major urinary, rectal and genital complications such as fistula, faecal impaction, hydronephrosis and urosepsis [1]. These rare complications are almost exclusively related to a long period of use and negligence of care. With regular follow-up, the majority of pessary complications can be avoided and kept to a minimum [9].

\section{Conclusion}

Pessary treatment is widely used for the treatment of pelvic organ prolapse. It can be considered a patientfriendly, minimally invasive treatment and appears to be safe. Most studies reported successful fitting trial over $85 \%$. Risk factors responsible for unsuccessful pessary fitting are short vaginal length, a large genital hiatus, prior history of hysterectomy and prior surgical repairs of POP. The compartment and stage of POP have not been reported to have any influence on successful pessary fitting. Fifty percent to $80 \%$ of women who were initially successfully fitted continued to use pessary at 1 year. Continuation rates at greater than 5 years range from $14 \%$ to $48 \%$. Consistent in most reports though are the improvements in both bulge and irritative bladder symptoms and the high satisfaction rates.

Sexual activity appears not to be a contraindication for pessary treatment; on the contrary, it seems to have a positive effect on sexual functioning. In comparison with POP surgery, 1-year outcomes in terms of prolapse symptoms, sexual functioning and quality of life seem similar with pessary use.

\section{Discussion}

The aim of this review was to set up a systematic review on articles that address health-related quality of life in pessary treatment of pelvic organ prolapse. The limitation of this review is the limited availability of published studies on that issue. Another limitation is that in most published papers, follow-up periods were short, usually less than 12 months. Long-term outcomes on the other hand were inconsistent.

The use of validated urogynaecological questionnaires in pessary treatment is still limited. In POP surgery, the use of these validated tools is well established. The few papers in which urogynaecological questionnaires were used do suggest improvements in health-related quality of life following pessary treatment. Comparison with other prolapse therapies is rare and, if so, not yet assessed in a randomised controlled trial.

More research is indicated, and it is our opinion that a randomised controlled trial comparing pessary use with surgical treatments of POP should be undertaken to determine its therapeutic position in the management of pelvic organ prolapse. Outcome measures of such a trial 
should be the change in urogenital bother and quality of life scores.

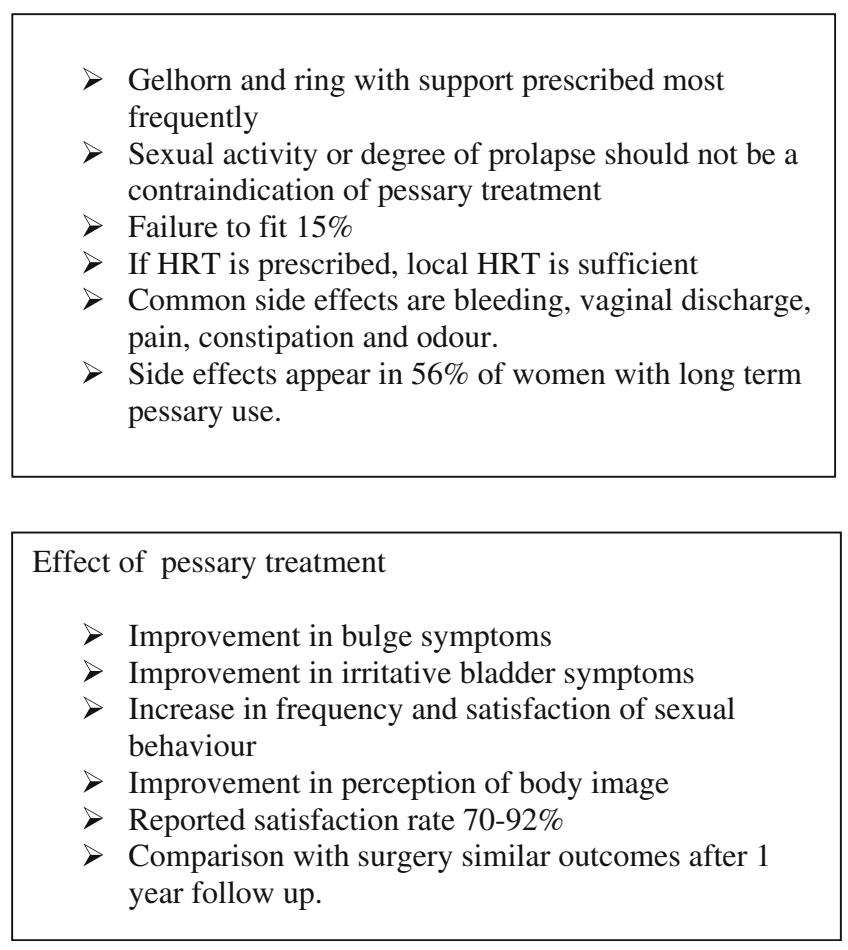

Conflicts of interest None.

Open Access This article is distributed under the terms of the Creative Commons Attribution Noncommercial License which permits any noncommercial use, distribution, and reproduction in any medium, provided the original author(s) and source are credited.

\section{References}

1. Jelovsek JE, Maher C, Barber MD (2007) Pelvic organ prolapse. Lancet 369(9566):1027-1038, 24

2. Adams E, Thomson A, Maher C, Hagen S. (2004) Mechanical devices for pelvic organ prolapse in women. Cochrane Database Syst Rev (2):CD004010

3. Cundiff GW, Weidner AC, Visco AG, Bump RC, Addison WA (2000) A survey of pessary use by members of the American Urogynecologic Society. Obstet Gynecol 95(6 Pt 1):931-935

4. Richter HE, Burgio KL, Brubaker L, Nygaard IE, Ye W, Weidner A et al (2010) Continence pessary compared with behavioral therapy or combined therapy for stress incontinence: a randomized controlled trial. Obstet Gynecol 115(3):609-617, 2010 March

5. Atnip SD (2009) Pessary use and management for pelvic organ prolapse. Obstet Gynecol Clin North Am 36(3):541-563

6. Cundiff GW, Amundsen CL, Bent AE, Coates KW, Schaffer JI, Strohbehn K et al (2007) The PESSRI study: symptom relief outcomes of a randomized crossover trial of the ring and Gellhorn pessaries. Am J Obstet Gynecol 196(4):405-408

7. Komesu YM, Rogers RG, Rode MA, Craig EC, Schrader RM, Gallegos KA et al (2008) Patient-selected goal attainment for pessary wearers: what is the clinical relevance? Am J Obstet Gynecol 198(5):577-577

8. Anders K (2004) Devices for continence and prolapse. BJOG 111 (Suppl 1):61-66

9. Arias BE, Ridgeway B, Barber MD (2008) Complications of neglected vaginal pessaries: case presentation and literature review. Int Urogynecol J Pelvic Floor Dysfunct 19(8):11731178

10. Doshani A, Teo RE, Mayne CJ, Tincello DG (2007) Uterine prolapse. BMJ 335(7624):819-823, 20

11. Onwude JL. (2007) Genital prolapse in women. Clin Evid (Online)

12. Shagam JY (2006) Pelvic organ prolapse. Radiol Technol 77 (5):389-400

13. Shah SM, Sultan AH, Thakar R (2006) The history and evolution of pessaries for pelvic organ prolapse. Int Urogynecol J Pelvic Floor Dysfunct 17(2):170-175

14. Thakar R, Stanton S (2002) Management of genital prolapse. BMJ 324(7348):1258-1262, 25

15. Trowbridge ER, Fenner DE (2005) Conservative management of pelvic organ prolapse. Clin Obstet Gynecol 48(3):668-681

16. Trowbridge ER, Fenner DE (2007) Practicalities and pitfalls of pessaries in older women. Clin Obstet Gynecol 50(3):709-719

17. Vierhout ME (2004) The use of pessaries in vaginal prolapse. Eur J Obstet Gynecol Reprod Biol 117(1):4-9, 10

18. Weber AM, Richter HE (2005) Pelvic organ prolapse. Obstet Gynecol 106(3):615-634

19. Abdool Z, Thakar R, Sultan AH, Oliver RS (2010) Prospective evaluation of outcome of vaginal pessaries versus surgery in women with symptomatic pelvic organ prolapse. Int Urogynecol J Pelvic Floor Dysfunct 16

20. Bai SW, Yoon BS, Kwon JY, Shin JS, Kim SK, Park KH (2005) Survey of the characteristics and satisfaction degree of the patients using a pessary. Int Urogynecol J Pelvic Floor Dysfunct 16 (3): $182-186$

21. Barber MD, Walters MD, Cundiff GW (2006) Responsiveness of the Pelvic Floor Distress Inventory (PFDI) and Pelvic Floor Impact Questionnaire (PFIQ) in women undergoing vaginal surgery and pessary treatment for pelvic organ prolapse. Am J Obstet Gynecol 194(5):1492-1498

22. Brincat C, Kenton K, Pat FM, Brubaker L (2004) Sexual activity predicts continued pessary use. Am J Obstet Gynecol 191(1):198200

23. Broens-Oostveen MC, Mom RM, Lagro-Janssen AL (2004) Genital prolapse; treatment and course in four general practices. Ned Tijdschr Geneeskd 148(29):1444-1448, 17

24. Clemons JL, Aguilar VC, Tillinghast TA, Jackson ND, Myers DL (2004) Risk factors associated with an unsuccessful pessary fitting trial in women with pelvic organ prolapse. Am J Obstet Gynecol 190(2):345-350

25. 122Clemons JL, Aguilar VC, Tillinghast TA, Jackson ND, Myers DL (2004) Patient satisfaction and changes in prolapse and urinary symptoms in women who were fitted successfully with a pessary for pelvic organ prolapse. Am J Obstet Gynecol 190 (4): $1025-1029$

26. Clemons JL, Aguilar VC, Sokol ER, Jackson ND, Myers DL (2004) Patient characteristics that are associated with continued pessary use versus surgery after 1 year. Am J Obstet Gynecol 191 (1):159-164

27. Fernando RJ, Thakar R, Sultan AH, Shah SM, Jones PW (2006) Effect of vaginal pessaries on symptoms associated with pelvic organ prolapse. Obstet Gynecol 108(1):93-99

28. Friedman S, Sandhu KS, Wang C, Mikhail MS, Banks E (2010) Factors influencing long-term pessary use. Int Urogynecol J Pelvic Floor Dysfunct 21(6):673-678 
29. Handa VL, Jones M (2002) Do pessaries prevent the progression of pelvic organ prolapse? Int Urogynecol J Pelvic Floor Dysfunct 13(6):349-351

30. Hanson LA, Schulz JA, Flood CG, Cooley B, Tam F (2006) Vaginal pessaries in managing women with pelvic organ prolapse and urinary incontinence: patient characteristics and factors contributing to success. Int Urogynecol J Pelvic Floor Dysfunct 17(2):155-159

31. Heit M, Rosenquist C, Culligan P, Graham C, Murphy M, Shott S (2003) Predicting treatment choice for patients with pelvic organ prolapse. Obstet Gynecol 101(6):1279-1284

32. Jones K, Yang L, Lowder JL, Meyn L, Ellison R, Zyczynski HM et al (2008) Effect of pessary use on genital hiatus measurements in women with pelvic organ prolapse. Obstet Gynecol 112(3):630-636

33. Kapoor DS, Thakar R, Sultan AH, Oliver R (2009) Conservative versus surgical management of prolapse: what dictates patient choice? Int Urogynecol J Pelvic Floor Dysfunct 20(10):1157-1161

34. Komesu YM, Rogers RG, Rode MA, Craig EC, Gallegos KA, Montoya AR et al (2007) Pelvic floor symptom changes in pessary users. Am J Obstet Gynecol 197(6):620-626

35. Kuhn A, Bapst D, Stadlmayr W, Vits K, Mueller MD (2009) Sexual and organ function in patients with symptomatic prolapse: are pessaries helpful? Fertil Steril 91(5):1914-1918

36. Lowenstein L, Gamble T, Sanses TV, van RH, Carberry C, Jakus S, Pham T et al (2010) Changes in sexual function after treatment for prolapse are related to the improvement in body image perception. J Sex Med 7(2 Pt 2):1023-1028

37. Maito JM, Quam ZA, Craig E, Danner KA, Rogers RG (2006) Predictors of successful pessary fitting and continued use in a nurse-midwifery pessary clinic. J Midwifery Womens Health 51 (2):78-84

38. Matsubara S, Ohki Y (2010) Can a ring pessary have a lasting effect to reverse uterine prolapse even after its removal? J Obstet Gynaecol Res 36(2):459-461

39. Mutone MF, Terry C, Hale DS, Benson JT (2005) Factors which influence the short-term success of pessary management of pelvic organ prolapse. Am J Obstet Gynecol 193(1):89-94

40. Nager CW, Richter HE, Nygaard I, Paraiso MF, Wu JM, Kenton K et al (2009) Incontinence pessaries: size, POPQ measures, and successful fitting. Int Urogynecol J Pelvic Floor Dysfunct 20(9):1023-1028

41. Patel M, Mellen C, O'Sullivan DM, Lasala CA. (2010) Impact of pessary use on prolapse symptoms, quality of life, and body image. Am J Obstet Gynecol 18

42. Powers $\mathrm{K}$, Lazarou $\mathrm{G}$, Wang A, LaCombe J, Bensinger G, Greston WM et al (2006) Pessary use in advanced pelvic organ prolapse. Int Urogynecol J Pelvic Floor Dysfunct 17(2):160-164

43. Sarma S, Ying T, Moore KH (2009) Long-term vaginal ring pessary use: discontinuation rates and adverse events. BJOG 116 (13):1715-1721

44. Jelovsek JE, Barber MD (2006) Women seeking treatment for advanced pelvic organ prolapse have decreased body image and quality of life. Am J Obstet Gynecol 194(5):1455-1461

45. Hopwood P, Fletcher I, Lee A, Al GS (2001) A body image scale for use with cancer patients. Eur J Cancer 37(2):189-197

46. Novi JM, Jeronis S, Morgan MA, Arya LA (2005) Sexual function in women with pelvic organ prolapse compared to women without pelvic organ prolapse. J Urol 173(5):16691672 